\title{
Glucosylceramide Synthase of Mouse Kidney: Further Characterization with an Improved Assay Method ${ }^{1}$
}

\author{
Girja S. Shukla and Norman S. Radin ${ }^{2}$ \\ Mental Health Research Institute, The University of Michigan, Ann Arbor, Michigan 48104-1687
}

Received May 1, 1990, and in revised form August 9, 1990

The synthesis of glucosylceramide from ceramide and UDP- $\left[{ }^{3} \mathbf{H}\right]$ glucose by mouse kidney homogenates is very sensitive to the concentration of tissue. This was shown to be due to the presence of a UDP-glc pyrophosphatase, which could be blocked by adding NAD to the medium. A new solvent partitioning system is described, containing $t$-butyl methyl ether, isopropyl alcohol, and aqueous sodium sulfate, which separates the original substrate (UDP- $\left[{ }^{3} \mathrm{H}\right] \mathrm{glc}$ ) from the enzyme product, $\left[{ }^{3} \mathrm{H}\right]$ cerebroside. A particular advantage of the solvent system is that only a single partitioning step is needed, without backwashes, and the enzyme product appears in the upper phase, making transfer to a counting vial more reliable. A novel incubation device, a thermostatically controlled ultrasonic bath, is used to produce highly uniform enzyme reaction rates. $\mathrm{Ca}^{2+}$, as well as $\mathrm{Mg}^{2+}$ and $\mathrm{Mn}^{2+}$, was found to be a good stimulator of the glucosyltransferase. The enzyme activity in kidney of 22 -day old mice, $\sim 240$ $\mathrm{pmol} / \mathrm{h} / \mathrm{mg}$ tissue, is significantly greater than previously demonstrated. The enzyme was stable in intact kidneys stored at $-70^{\circ} \mathrm{C}$ but unstable at $4^{\circ} \mathrm{C}$. The enzyme, when acting on endogenous ceramides, showed no demonstrable glucosylation of the $\mathrm{C}_{24}$ family of ceramides although this family is the predominant one in kidney. (c) 1990 Academic Press, Inc.

Previous observations suggest that glucosylceramide $(\mathrm{GlcCer})^{3}$ and its more highly glycosylated products play major roles in kidney function. The kidney of male mice seems to synthesize and excrete into the urine relatively large amounts of these lipids (1). Male mice treated with

\footnotetext{
${ }^{1}$ Supported in part by NIH Grant NS-03192. N.S.R. is an NIH Senator Jacob Javits Neuroscience Investigator awardee.

${ }^{2}$ To whom correspondence should be addressed at Neuroscience Lab. Bldg., 1103 E. Huron, Ann Arbor, MI 48104-1687, U.S.A.

${ }^{3}$ Abbreviations used: GlcCer, glucosylceramide; $\mathrm{C} / \mathrm{M} / \mathrm{W}$, chloroform/ methanol/water mixtures, (v/v); Chapso, $\{3-[(3$-cholamidopropyl)-dimethylammonio]-2-hydroxy-1-propanesulfonate $\}$.
}

multiple injections of a GlcCer synthase inhibitor, Dthreo - 1-phenyl-2 - decanoylamino - 3-morpholino-1-propanol, developed kidneys of decreased size (2). In addition, we found in an initial study that the level of GlcCer in kidneys of mice treated with only one dose of the inhibitor rapidly developed a decreased level of GlcCer. One would expect from these observations that there is a rapid turnover of this lipid in kidney and that the level of the synthase is high. However, previous studies of the kidney enzyme found very low transferase activity $(3,4)$. We confirmed this observation, using an improved assay technique which gave reasonably high activities in brain and liver (5). Moreover, we found that the use of larger amounts of kidney homogenate in the incubation tube did not produce proportionally higher activities, even at a low degree of ceramide conversion. These observations, and the finding that adding kidney homogenate to liver homogenate lowered the activity seen with liver alone, indicated the presence of some inhibitory material(s) in kidney. This paper is the result of an effort to eliminate the effect of the interfering kidney component(s) and obtain a realistic measure of the total transferase in that organ. In the course of the study, marked improvements were made in the basic assay procedure which should be of more general interest.

\section{MATERIALS AND METHODS}

Animals. Mice of the ICR strain, from Harlan-Sprague-Dawley, were obtained at a weight of $20-22 \mathrm{~g}$ and kept in our animal room until they weighed 30 to $40 \mathrm{~g}$.

Chemicals. UDP-D- $\left[6-{ }^{3} \mathrm{H}\right]$ glucose was from Amersham. Most other reagents were from Sigma Chemical Co. GlcCer was prepared from a Gaucher spleen (6), and sulfatide was prepared from pig brain as the sodium salt (7). Chapso was from Calbiochem. Silica gel 60, on precoated TLC plates and packed into columns (230/400 mesh), was from Merck. Octanoyl sphingosine was prepared by acylation of the sphingol (5), which had been isolated from brain galactosylceramide. $\mathrm{C}_{\mathbf{8}}$-GlcCer was prepared similarly, from glucosyl sphingosine, prepared by alkaline hydrolysis of GlcCer (8). Conduritol B epoxide was prepared from inositol (9).

Assay method. Glucosyltransferase was assayed with $100 \mu \mathrm{M}$ UDP glc $(80,000 \mathrm{cpm}), 2 \mathrm{mM} \beta-\mathrm{NAD}$ (free acid), $1 \mathrm{mM}$ dithioerythritol, $2 \mathrm{mM}$ 
$\mathrm{Na}_{2}$ EDTA, $10 \mathrm{mM} \mathrm{MgCl}{ }_{2}, 0.1 \mathrm{M}$ Tris-Cl${ }^{-} \mathrm{pH} 7.4$ (at $37^{\circ} \mathrm{C}$ ), and liposomal substrate, in a total volume of $0.2 \mathrm{ml}$. The lipoidal substrate was prepared by evaporating to dryness a solution in $\mathrm{C} / \mathrm{M}$ of $4 \mu \mathrm{mol}(1.70 \mathrm{mg}) \mathrm{N}$ octanoyl sphingosine, $11.3 \mathrm{mg}$ of dioleoyl phosphatidylcholine, and 2 $\mathrm{mg}$ of brain $\mathrm{Na}$ sulfatide. The residue was suspended in cyclohexane and lyophilized overnight as a thin layer in a $15-\mathrm{ml}$ centrifuge tube. The resultant powder was dispersed in $1 \mathrm{ml}$ water by sonicating with a probe immersed $\sim 3 / 4$ in., with the tube in an ice bath. The power cycle was $60 \mathrm{~s}$ on and $30 \mathrm{~s}$ off, for a total of $7.5 \mathrm{~min}$. This almost clear suspension could be refrigerated and used for a week, provided it was resonicated the same way just before use.

Each incubation vessel (a new $16 \times 125$-mm screw cap disposable borosilicate tube) was loaded with the cocktail, $50 \mu \mathrm{l}$ of the liposomal mixture, and an aliquot of kidney freshly homogenized in 9 vol of water. The homogenate was pipetted into duplicate incubation tubes immediately after a brief vortexing at low speed in a wide tube.

Incubation was carried out in an ultrasonic bath at $37^{\circ} \mathrm{C}$ for $30 \mathrm{~min}$, after which the tubes were immersed in ice and $1 \mathrm{ml}$ of isopropanol and $0.8 \mathrm{ml}$ of aqueous $\mathrm{Na}_{2} \mathrm{SO}_{4}$ (40 mg anhydrous) were added. After brief vortexing, $6 \mathrm{ml}$ of t-butyl methyl ether were added from a dispensing pipettor and vortexing for $1 \mathrm{~min}$ was carried out. The mixture was centrifuged for $10 \mathrm{~min}$ at $2000 \mathrm{rpm}$ in an International centrifuge. Six out of the seven milliliters in the upper layer, containing the labeled GlcCer formed, was transferred with a volumetric pipet and evaporated to dryness with nitrogen in a plastic counting vial in a $45^{\circ} \mathrm{C}$ water bath. The residue was dissolved in $0.3 \mathrm{ml}$ of water and $5 \mathrm{ml}$ of Universol scintillation solvent (ICN Biomedicals) with shaking for $30 \mathrm{~min}$, then counted.

Examination of UDP-glc degradation. Postreaction analysis of remaining UDP-glc was carried out with alkaline phosphatase from Escherichia coli (Sigma No. P-4151), which was added to hydrolyze any glucose 1-phosphate formed by the action of nucleotide-sugar pyrophosphatase. The reaction was carried out and analyzed by ion exchange according to the method of Byrd et al. (10). We found it necessary to elute the $\left[{ }^{3} \mathrm{H}\right]$ glucose from the ion exchange column with $3 \mathrm{ml}$ of water, instead of $0.2 \mathrm{ml}$, as reported.

Characterization of the biosynthesized GlcCer. The lipids in the upper layer obtained by the partition solvents were separated by TLC with $\mathrm{C} / \mathrm{M} / \mathrm{W}(21 / 7 / 1)$ together with carrier $\mathrm{C}_{8}$-GlcCer and natural, Gaucherderived GlcCer. The spots were visualized with a fluorogenic reagent, primulin (11), scraped, and counted after dissolving the silica gel in aqueous HF (12). The rest of the plate was also counted. Only two of the three GlcCer spots were radioactive, with $\frac{1}{3}$ of the activity in the GlcCer derived from the $\mathrm{C}_{16}$ and $\mathrm{C}_{18}$ fatty acid ceramides and $\frac{2}{3}$ in the $\mathrm{C}_{8} \mathrm{GlcCer}$. A more precise identification was carried out by radioautography, which showed that the very long chain cerebrosides $\left(\mathrm{C}_{24}\right.$ family) were not noticeably radioactive, in keeping with the dominance of the shorter chains found in kidney GlcCer. The endogenous ceramides in kidney are mainly of the $C_{24}$ type, which do not act as glucose acceptors in our incubations.

\section{RESULTS}

Development of the extraction procedure. In previous procedures, the biosynthesized GlcCer was isolated by partitioning with chloroform, methanol, and water. Several washes of the chloroform-rich layer were needed to remove nonlipid radioactive material; this resulted in some loss of the $\mathrm{C}_{8}$-GlcCer, which is more polar than natural GlcCer. Therefore we investigated other solvent systems, particularly seeking a system in which the upper layer contained the lipid.

A large volume of incubation mixture $(5 \mathrm{ml})$ was used to prepare radioactive GlcCer for evaluating different extraction procedures. The $\left[{ }^{3} \mathrm{H}\right] \mathrm{GlcCer}$ was purified by silica gel chromatography with $\mathrm{C} / \mathrm{M}(85 / 15)$ and the radioactive product (which contained some labeled long chain GlcCer as well as $\mathrm{C}_{8}$-GlcCer) was used in the standard incubation mixture containing nonradioactive UDP-glc and boiled enzyme. The partitioning system finally developed, described in the Methods section, yielded 97-99\% recovery of GlcCer and only $\sim 40 \mathrm{cpm}$ from the labeled UDP-Glc $(80,000 \mathrm{cpm})$ in the upper layer. The $\mathrm{Na}_{2} \mathrm{SO}_{4}$ in the partitioning system served to force the glycolipid into the organic-rich layer.

The need for pyridine nucleotides. Since our initial trials with kidney had demonstrated the presence of an interfering material, we tried removing it by differential centrifugation or by extraction with a zwitterionic detergent (Chapso). These approaches failed, like similar attempts with brain and UDP-gal (13). Sphingosine, which might be produced during the incubation by ceramidase action on the octanoyl sphingosine or endogenous ceramide (14), was shown not to inhibit GlCer synthase even at $10 \mu \mathrm{M}$. This point is of interest in view of the recent reports showing marked effects of sphingosine on specific enzymes.

We next considered the possibility that a significant portion of the UDP-glc was being destroyed by nucleotide pyrophosphatase, which is known to occur in various membrane fractions $(13,15,16)$ and which has been found to interfere with several sugar transferase assays (17-20). Various nucleotides were tested as possible competitive substrates of the enzyme. Only nicotinamide nucleotides produced a distinct enhancement (Table I).

The data in this table also show that the labeled UDPglc, if diverted by conversion to UDP-gal by an epimerase, did not lead to the synthesis of galactosylceramide. If it

\section{TABLE I}

Effect of Added Nucleotides on the Synthesis of Glucocerebroside by Kidney Homogenate ${ }^{a}$

\begin{tabular}{lc}
\hline \multicolumn{1}{c}{ Additions } & \% of control \\
\hline ATP & 105 \\
UMP & 106 \\
UDP-glucuronic acid & 105 \\
UDP-galactose & 108 \\
ADP-glucose & 101 \\
CDP-glucose & 87 \\
GDP-glucose & 111 \\
CDP-choline & 93 \\
NAD & 196 \\
NADH & 187 \\
NADP & 175 \\
NADPH & \\
NADP + NAD & 168 \\
\end{tabular}

a The standard incubations were used with $4 \mathrm{mg}$ of kidney except for the omission of NAD. The added nucleotides were at $0.5 \mathrm{mM}$ except for ATP, which was $2 \mathrm{mM}$. The yield of $\left[{ }^{3} \mathrm{H}\right]$ glucocerebroside in the control tubes was $259 \mathrm{pmol}$ GlcCer formed in $30 \mathrm{~min}$. 


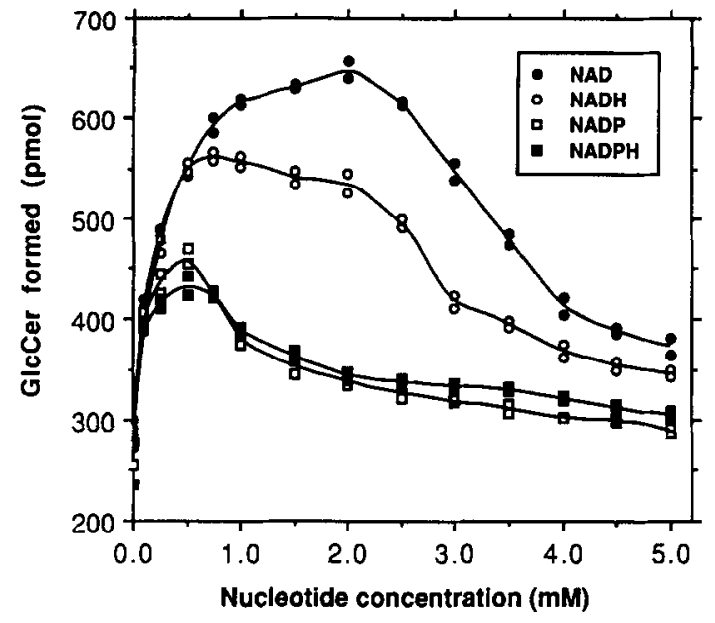

FIG. 1. The effect of nicotinamide nucleotides on the formation of GlcCer. Each point shown is derived from a single tube that was incubated for $30 \mathrm{~min}$ with $4 \mathrm{mg}$ of kidney homogenate as described in the Methods section.

had, the addition of unlabeled UDP-gal would have reduced the amount of radioactive cerebroside formed.

The effectiveness of nicotinamide nucleotides was studied further (Fig. 1). This study showed that NADP and $\mathrm{NADPH}^{+}$were less effective than NAD and $\mathrm{NADH}^{+}$, with maximal stimulation at $0.5 \mathrm{mM}$. $\mathrm{NADH}^{+}$also showed a maximum at a relatively low concentration, while NAD was best, peaking at $2 \mathrm{mM}$. Accordingly this was adopted for the later assays.

The use of higher than optimal nucleotide concentrations lowered the yield of GlcCer (Fig. 1), raising the question whether one could obtain even higher activities than those seen at $2 \mathrm{mM}$ NAD. It was observed that the optimal concentration of NAD was lower $(1 \mathrm{mM})$ if only $1 \mathrm{mg}$ of tissue was used. Under this condition, where the interfering material was less concentrated, the observed specific activity at $1 \mathrm{mM}$ NAD was $\sim 10 \%$ higher than at $2 \mathrm{mM}$. A similar effect was obtained when the UDP-glc concentration was increased to $400 \mu \mathrm{M}$; NAD was now slightly inhibitory. It is much more economical, however, to use NAD than to use more radioactive UDP-glc.

If the pyridine nucleotides enhance the formation of GlcCer by blocking pyrophosphatase action on UDP-glc, one would expect that the reaction would slow down with time in the absence of the nucleotide. This proved to be the case (Fig. 2). When $4 \mathrm{mg}$ of tissue were used in the incubation, the reaction stopped within $20 \mathrm{~min}$ in the absence of NAD but persisted until $75 \mathrm{~min}$ in the presence of $2 \mathrm{mM}$ NAD. The curve seemed straight enough during the first $30 \mathrm{~min}$ to make this a practical incubation time. Evidently the endogenous inhibitor of cerebroside synthesis reported in rat brain microsomes (21), if present in kidney, does not have a noticeable effect in incubations with up to $6 \mathrm{mg}$ of tissue.

To confirm the conclusion that the beneficial effect of NAD depended on its blocking kidney pyrophosphatase

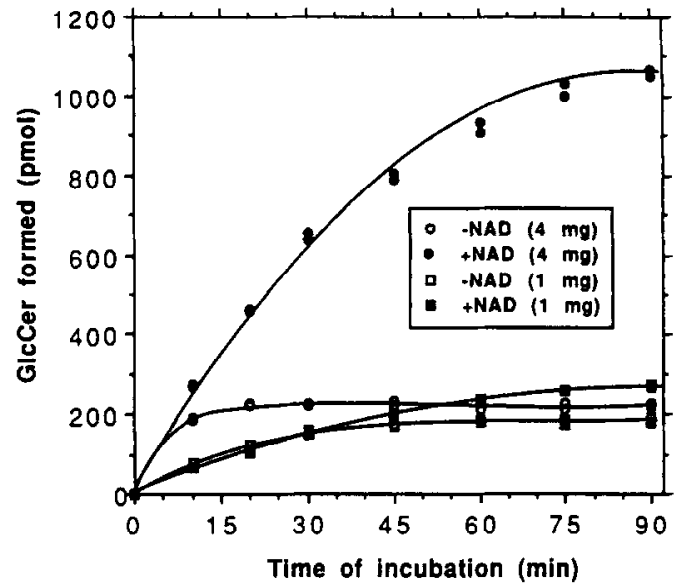

FIG. 2. Formation of GIcCer from labeled UDP-glc as a function of time. Experiments were run with $4 \mathrm{mg}$ of kidney $(O$ and $\bullet)$ and with 1 mg of kidney ( $\square$ and $\square$ ). All incubation tubes contained 0 or $2 \mathrm{mM} \mathrm{NAD}$, as described in the Methods section.

action on UDP-glc, we analyzed the aqueous layer after partitioning the incubation mixture with $\mathrm{C} / \mathrm{M} / \mathrm{W}$ (22). This should contain the unreacted UDP-glc and, perhaps, glucose 1-phosphate. The aqueous layer was evaporated to dryness with nitrogen, then incubated with $0.2 \mathrm{ml}$ water containing 0.25 units of alkaline phosphatase as described above. A portion of the solution containing $\left[{ }^{3} \mathrm{H}\right]$ glucose, isolated by ion exchange, was counted by liquid scintillation (Table II).

It was apparent that a substantial part of the UDP-glc was hydrolyzed in the absence of NAD, the amount increasing with incubation time and tissue concentration. The protection by NAD, at $2 \mathrm{mM}$, was almost complete. It is interesting to note that lyophilized kidney membranes, assayed by a different method (3), could produce GlcCer at a steady rate for several hours. This might be

TABLE II

UDP-Glc Hydrolysis by Kidney Homogenate under Different Incubation Conditions ${ }^{a}$

\begin{tabular}{cccc}
\hline $\begin{array}{c}\text { NAD } \\
(- \text { or }+)\end{array}$ & $\begin{array}{c}\text { Tissue } \\
(\mathrm{mg})\end{array}$ & $\begin{array}{c}\text { Incubation time } \\
(\text { min })\end{array}$ & $\begin{array}{c}\text { \% of UDP-Glc } \\
\text { hydrolyzed }\end{array}$ \\
\hline- & 4 & 30 & 81 \\
+ & 4 & 30 & 17 \\
- & 4 & 10 & 45 \\
+ & 4 & 10 & 10 \\
- & 1 & 30 & 30 \\
+ & 1 & 30 & 8 \\
- & 1 & 10 & 15 \\
+ & 1 & 10 & 7 \\
- & 4 (boiled) & 30 & 6 \\
+ & 4 (boiled) & 30 & 5 \\
\hline
\end{tabular}

a The incubations were carried out as described in the Methods section with zero or $2 \mathrm{mM}$ NAD. 
the result of inactivation of UDP-glc pyrophosphatase by lyophilization or by treatment with benzene.

'The effect of NAD on the synthesis of GlcCer was confirmed by examining the radioactive products by TLCradioautography. Omitting NAD from the mixture resulted in a reduction of both kinds of GlcCer $\left(\mathrm{C}_{18}\right.$ and $\mathrm{C}_{8}$ ).

pH optimum. The standard conditions of assay, with and without NAD, were used with $0.1 \mathrm{M}$ Tris- $\mathrm{Cl}^{-} \mathrm{pH} 7-$ 8.6 (at $37^{\circ} \mathrm{C}$ ). In the tubes in which pyrophosphatase activity had little effect (those containing NAD or only 1 $\mathrm{mg}$ of tissue), the optimal $\mathrm{pH}$ was clearly 7.4. A flattened activity peak was obtained with the tubes containing 4 $\mathrm{mg}$ of tissue, but no NAD, which may reflect the effect of $\mathrm{pH}$ on the pyrophosphatase.

Effects of divalent cations. Using the basic assay procedure, but changing the divalent cation composition of the incubation mixture, we found that $\mathrm{Mg}^{2+}$ was the most stimulatory, but $\mathrm{Mn}^{2+}$ and $\mathrm{Ca}^{2+}$ were not much inferior (Fig. 3). The optimal concentration for all three was 10 $\mathrm{mM}$, although $\mathrm{Mn}^{2+}$ yielded a similar activity at $15 \mathrm{mM}$. The percentage stimulation by the exogenous cations was not as great as that seen in previous studies based on membrane preparations, probably because of the endogenous cations already present in whole homogenates. The efficacy of $\mathrm{Ca}^{2+}$ for glucosyltransferase appears to be a new finding. Ferrous ions, $\mathrm{Cu}^{2+}$, and $\mathrm{Zn}^{2+}$ all inhibited, even at $5 \mathrm{mM}$.

Effects of changing incubation components. While the omission of dithioerythritol and EDTA did not have a marked effect, the omission of $\mathbf{M g}^{2+}$ (with or without omitting EDTA) resulted in a distinct lowering of activity (Table III). A striking decrease was obtained when the Tris buffer concentration was doubled, which may indicate the advisability of studying other buffers. While other

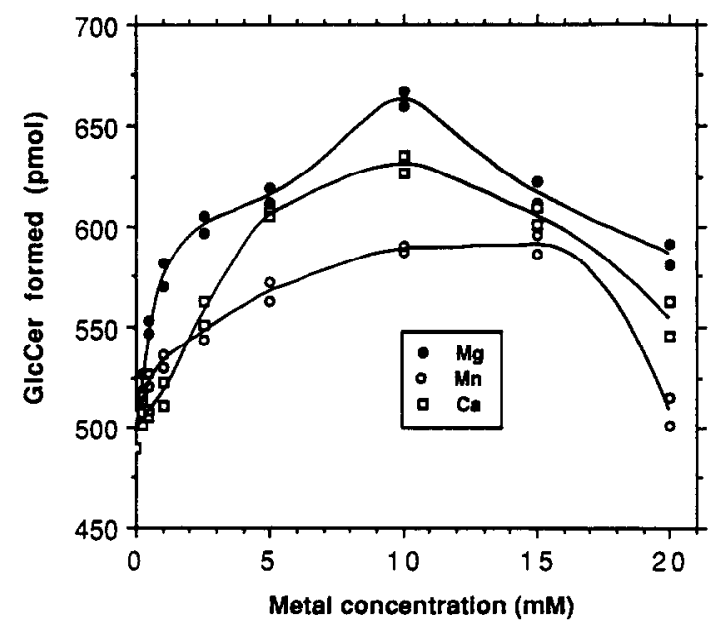

FIG. 3. Effect of cation concentration on formation of GlcCer. The standard assay conditions were used, except for the content of divalent cation.
TABLE III

Effects of Changes in the Incubation Medium on the Synthesis of Glucocerebroside ${ }^{a}$

\begin{tabular}{lc}
\multicolumn{1}{c}{ Conditions } & \% of control \\
\hline -Dithioerythritol & 91 \\
-EDTA & 93 \\
- $\mathrm{Mg}^{2+}$ & 75 \\
-EDTA and $-\mathrm{Mg}^{2+}$ & 61 \\
Tris-doubled concentration & 42 \\
+Conduritol B epoxide $50 \mu \mathrm{M}$ & 98 \\
+CHAPSO 6.34 mM & 55 \\
+Mixed ceramide 0.2 $\mu$ mol (instead of $\mathrm{C}_{8}$ ) & 84 \\
Endogenous ceramide only & 34 \\
\hline
\end{tabular}

a The incubation tubes contained $4 \mathrm{mg}$ of kidney and were treated as described in the Methods section.

researchers have used some other buffers (23), the concentrations were generally so low that they could not be useful with whole tissue homogenates.

Chapso, like other detergents we have tested with ceramide glucosyl- and galactosyl-transferases $(24,25)$, was inhibitory but not as strongly so. Conduritol B epoxide was added with the idea of blocking the hydrolysis of the $\left[{ }^{3} \mathrm{H}\right] \mathrm{GlcCer}$ formed (26) but it had no effect. This may indicate that glucoceramidase, under the conditions used, has no activity or that freshly formed GlcCer is inaccessible to the hydrolase. A mixture of ceramides derived from brain sphingomyelin $\left(\mathrm{C}_{24}\right.$ and $\mathrm{C}_{18}$ families, Sigma) proved to be fairly effective as a substrate, even though the liposomal suspension was rather opaque. When no exogenous ceramide was added, there was a $66 \%$ reduction in activity. Mouse kidney contains only $\sim 0.7 \mathrm{nmol}$ of ceramides in $4 \mathrm{mg}$ (details to be published), which is much less than the $200 \mathrm{nmol}$ of $\mathrm{C}_{8}$-ceramide that we added to the incubation system. It is apparent that endogenous ceramide is utilized more efficiently than exogenous ceramide, possibly because of the method used to bring the substrate into contact with the enzyme.

Effect of tissue concentration. The observed activity was proportional to the weight of kidney up to at least 6 $\mathrm{mg}$ per tube $(30 \mathrm{mg} / \mathrm{ml})$, provided NAD was present (Fig. 4). Without NAD, there was no further increase in activity when more than $3 \mathrm{mg}$ of tissue was used. This is evidently the result of the complete destruction of the UDP-glc (see Table II).

Subcellular distribution. Study of glucosyltransferase activity in kidney microsomal preparations showed a marked need for NAD (Fig. 5). Evidently UDP-glc pyrophosphatase activity is significant in this subcellular fraction. It is interesting that at the lowest concentration of microsomes tested, where UDP-glc breakdown would be minimal, $2 \mathrm{mM}$ NAD was slightly inhibitory, as noticed before with whole homogenate. This inhibition was not visible with $0.5 \mathrm{mM} \mathrm{NAD}$, which gave protection up to 


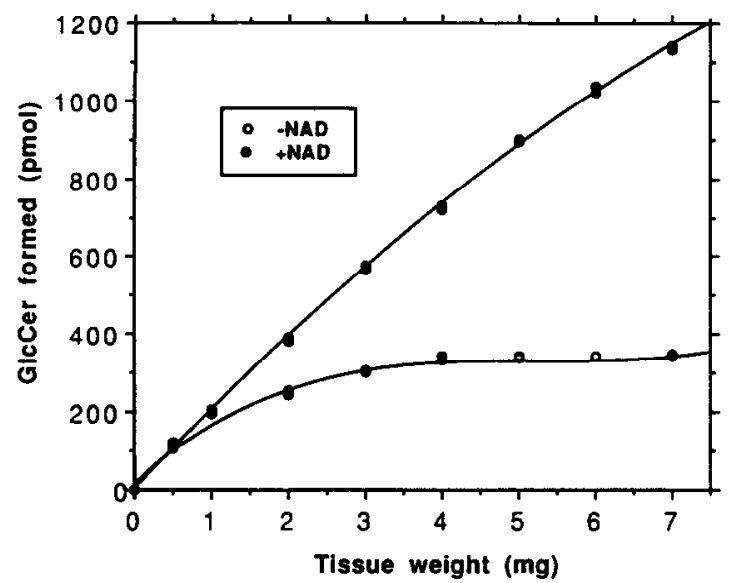

FIG. 4. Effect of tissue concentration on yield of GlcCer. All incubation tubes contained 0 or $2 \mathrm{mM}$ NAD, as described in the Methods section.

the $4 \mathrm{mg}$ level. Presumably, at the higher microsome levels, the NAD pyrophosphatase (27) hydrolyzed a major part of the NAD.

Examination of larger subcellular particles showed that glucosyltransferase is also present in the nuclear-debris (755g) and crude mitochondrial fractions (9750g). In the latter case, there was only a minor inhibitory effect of higher tissue concentrations and addition of NAD showed little effect (Fig. 6). This finding is probably due to a relatively low pyrophosphatase activity in this fraction, a point noted before with brain UDP-gal pyrophosphatase (13). In the case of the nuclear-debris fraction, NAD exerted a protective effect, visible at the higher membrane levels. The concave shape of the curve (not immediately noticeable in the figure) from the NAD-supplemented incubations, which was observed twice, suggests the presence of an endogenous transferase stimulator. In this study, the data are shown for $0.5 \mathrm{mM} \mathrm{NAD} ; 2 \mathrm{mM}$ NAD was inhibitory.

Stability of kidney GlcCer synthase. Comparing the two kidneys of each mouse, we found that the specific activity of the glucosyltransferase in intact kidneys was unaffected by $>90$ days of storage at $-70^{\circ} \mathrm{C}$. Moreover, the enzyme activity in microsomes, stored in $0.32 \mathrm{M}$ sucrose solution at $-70^{\circ} \mathrm{C}$ in portions, was also highly stable. This contrasts with the much lower stability found in lyophilized mouse kidney membranes $(3,4)$. However, after overnight storage at $4^{\circ} \mathrm{C}, 53 \%$ of the activity in intact kidney was lost.

\section{DISCUSSION}

The NAD effect. A striking finding from this study is the relatively specific stabilization of UDP-glc by NAD. While one could postulate that the NAD blocks some nonhydrolytic enzyme from acting on the nucleotide sugar, such as UDP-glc epimerase, our demonstration that hydrolytic products formed in the absence of NAD (Table

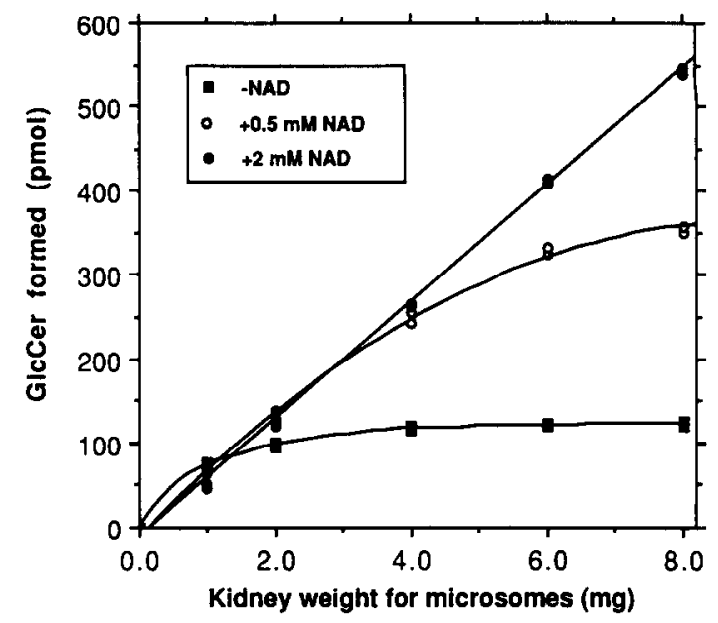

FIG. 5. Synthesis of GlcCer by kidney microsomes (sedimenting between $9750 \mathrm{~g}$ and $135,000 \mathrm{~g} \times 60 \mathrm{~min}$ ), with and without added NAD. The yield of protein in the microsomal preparation was $23 \mu \mathrm{g} / \mathrm{mg}$ tissue.

II) strongly suggests that the NAD acts to block a nucleotide pyrophosphatase. A similar conclusion was drawn with $\mathrm{NADH}^{+}$and a Golgi-rich fraction from porcine submaxillary glands in a system for the biosynthesis of GlcCer (28). In that system, the detergent Chaps was found to stimulate the utilization of exogenous ceramide but in our system the very similar detergent, Chapso, was found to be inhibitory (Table III).

It is surprising that so many of the nucleotides tested (Table I) were unable to inhibit the kidney enzyme and it seems likely that pyrophosphatases must consist of a family of relatively specific phosphatases, each acting on a different group of nucleotides, each sensitive to different substances. Several studies support this interpretation. The microsomal rat liver enzyme acting on UDP-gal was inhibited only by certain nucleotides and not by others

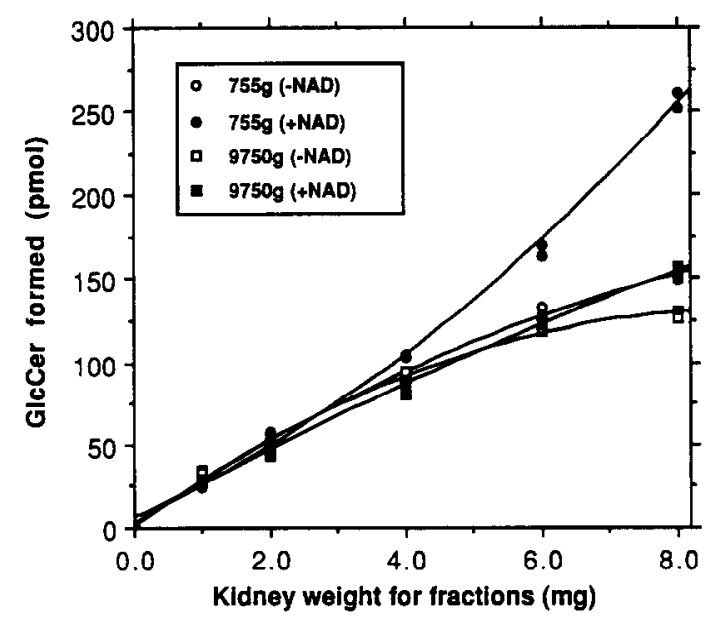

FIG. 6. Synthesis of GlcCer, with and without $0.5 \mathrm{mM} \mathrm{NAD}$, by nuclear-debris $(755 \mathrm{~g} \times 10 \mathrm{~min})$ and crude mitochondria $(9750 \mathrm{~g} \times 10 \mathrm{~min})$. 
(15). Similar specificity was found with a purified pyrophosphatase from rat liver nuclei (16), which hydrolyzed UDP-glc but was inhibited strongly by UDP-glucuronic acid, UMP, and ATP. None of these protected the UDPglc in our whole kidney homogenate. In the latter study (16), evidence was found for multiple pyrophosphatases. Rat kidney was found to have high pyrophosphatase activity against UDP-glucuronic acid (29), yet we did not find any protective effect of this sugar nucleotide, which suggests that two different pyrophosphatases are present. A similar conclusion can be drawn from the observation that ATP inhibits the pyrophosphatase acting on UDP$N$-acetylglucosamine (30).

The problem of blocking interference by pyrophosphatases has been treated also by preincubation with EDTA and trypsin inhibitor (18), a zinc chelator plus a nucleotide (17), and-for a very short period-with AMP (20).

Comparison of assay methods. In an age study (data not shown here), we found that the specific activity in 21day male mouse kidneys was $238 \mathrm{pmol} / \mathrm{h} / \mathrm{mg}$ tissue. This value can be compared with previously published values. Costantino-Ceccarini and Morell (3) reported a maximal, saturating value of $450 \mathrm{pmol} / \mathrm{h} / \mathrm{mg}$ protein for 22 -day mice. This corresponds to $\sim 68 \mathrm{pmol} / \mathrm{h} / \mathrm{mg}$ tissue, assuming a protein concentration of $15 \%$. This value was obtained with a debris-free highspeed membrane preparation which we assume to have the same specific activity as whole homogenates. An important difference between the two methods is that we could use larger amounts of tissue without being limited by the plateau found in the nonNAD method, which limited the maximum observed activity and necessitated the use of more tritium in the precursor. Moreover our assay avoids the problem of variable yields and purities of purified membranes, since we use whole tissue. However, the use of lyophilized, benzenetreated membranes allowed the reaction to proceed for a longer time without slowing down, thereby reducing the need for more tritium in the precursor.

A similar difference could be seen when lyophilized mouse kidney microsomes were assayed with liposomal ceramide (4). This study found $700 \mathrm{pmol} / \mathrm{h} / \mathrm{mg}$ protein for 33-day mice, a value much lower than the activity we found ( $3000 \mathrm{pmol} / \mathrm{h} / \mathrm{mg}$ protein) for our NAD-protected microsomes (Fig. 5).

It is interesting to note that kidney membranes, after lyophilization and treatment with henzene, were found to yield very little GlcCer if exogenous ceramide was not added (3). It seems likely that some of the endogenous ceramide is extracted by this treatment and rendered unavailable to the synthase.

Special features of the assay. An important time-saving feature of our new partitioning system is that only a single partitioning step is needed, without backwashes. Moreover, the enzyme product appears in the upper phase, so it can be transferred to the counting vial more con- veniently and with less danger of contamination with the highly radioactive water-rich phase. The latter feature is important for achieving a high degree of reproducibility. The solvent volumes were chosen to produce good vortexing action in the confines of the incubation tube, yet allow the use of a transfer pipet of relatively high precision. Our solvent system should prove useful in analogous assays of galactosylceramide and lactosylceramide synthases and other lipid synthases assayed with a hydrophilic labeled precursor.

The use of a thermostatically controlled ultrasonic bath for the incubation is a novel approach of general value to enzymologists. The reaction rate between insoluble enzyme, the water-soluble factors, and suspended liposomes - a 3-phase reaction-must depend to some extent on the degree of agitation of the mixture. When we used the customary reciprocating-action water bath, we noticed that the tissue particles adhered to the test tube, forming a ring, and that the variability was unexpectedly high so that it was necessary to run triplicate incubations. With the new method, the homogenate remained in suspension and the average deviation from the mean between duplicates for 50 pairs of values, was $2.6 \%$ of the means. This is comparable to that found with homogeneous enzyme radioassays carried out in standard shakers. The variability was lower than $2.6 \%$ for the more active preparations. Thus this feature of our method, like the new partitioning system, acts to speed the assay and reduce the cost of labeled substrate.

While many biochemists believe that ultrasonic baths denature enzymes, our own tests have shown that a membrane-bound enzyme, glucosyltransferase, and a soluble enzyme, alkaline phosphatase, are stable for at least 30 min. Moreover, there are many papers recommending the extraction of enzymes from tissues or tissue homogenates with ultrasonic probes-which produce far stronger ultrasonic pulses (see (31)).

\section{REFERENCES}

1. Williams, M. A., Gross, S. K., Evans, J. E., and McCluer, R. H. (1988) J. Lipid Res. 29, 1613-1619.

2. Inokuchi, J., Mason, I., and Radin, N. S. (1987) Cancer Lett. 38 23-30.

3. Costantino-Ceccarini, E., and Morell, P. (1973) J. Biol. Chem. 248. 8240-8246.

4. Kodama, S., Igisu, H., Siegel, D. A., and Suzuki, K. (1982) J. Neu rochem. 39, 1314-1318.

5. Vunnam, R. R., and Radin, N. S. (1979) Biochim. Biophys. Acta 573, 73-82.

6. Radin, N. S. (1976) J. Lipid Res. 17, 290-293.

7. Hara, A., and Radin, N. S. (1979) Anal. Biochem. 100, 364-370.

8. Radin, N. S. (1974) Lipids 9, 358-360.

9. Lee, K. J., Boyd, S. A., and Radin, N. S. (1985) Carbohydr. Res. 144, 148-154.

10. Byrd, J. C., Fearney, F. J., and Kim, Y. S. (1985) J. Biol. Chem. 260, 7474-7480. 
11. Skipski, V. (1975) in Methods in Enzymology (Lowenstein, J. M., Ed.), Vol. 35, pp. 396-428, Academic Press, San Diego.

12. Shaw, W. A., Harlan, W. R., and Bennett, A. (1971) Anal. Biochem. 43, 119-122.

13. Satomi, D., and Kishimoto, Y. (1981) J. Neurochem. 36, 476-482.

14. Sugita, M., Williams, M., Dulaney, J. T., and Moser, H. W. (1975) Biochim. Biophys. Acta 398, 125-131.

15. Mookerjea, S., and Yung, J. W. M. (1975) Arch. Biochem. Biophys. 166, 223-236.

16. Schliselfeld, L. H., van Eys, J., and Touster, O. (1965) J. Biol. Chem. 240, 811-818.

17. Faltynek, C. R., Silbert, J. E., and Hof, L. (1981) J. Biol. Chem. 256, 7139-7141.

18. Lau, J. T. Y., and Carlson, D. M. (1981) J. Biol. Chem. 256, 71427145 .

19. Mookerjea, S. (1979) Canad. J. Biochem. 57, 557-565.

20. Vessey, D. A., and Zakim, D. (1975) Eur. J. Biochem. 53, 499-504.

21. Costantino-Ceccarini, E., and Suzuki, K. (1978) J. Biol. Chem. 253, 340-342.
22. Folch, J., Lees, M., and Sloane Stanley, G. H. (1957) J. Biol. Chem. 226, 497-509.

23. Costantinu-Ceccarini, E., and Cestelli, A. (1981) in Methods in Enzymology (Lowenstein, J. M., Ed.), Vol. 72, pp. 384-391, Academic Press, San Diego.

24. Brenkert, A., and Radin, N. S. (1972) Brain Res. 36, 183-193.

25. Morell, P., and Radin, N. S. (1969) Biochemistry 8, 506-512.

26. Kanfer, J. N., Legler, G., Sullivan, J., Raghavan, S. S., and Mumford, R. A. (1975) Biochem. Biophys. Res. Commun. 67, 85-90.

27. Kornberg, A., and Lindberg, O. (1948) J. Biol. Chem. 176, 665-677.

28. Coste, H., Martel, M.-B., Azzar, G., and Got, R. (1985) Riochim. Biophys. Acta 814, 1-7.

29. Conney, A. H., and Burns, J. J. (1961) Biochim. Biophys. Acta 54. 369-372.

30. Pattabiraman, T. N., Varma, T. N. S., and Bachhawat, B. K. (1964) Biochim. Biophys. Acta 83, 74-83.

31. Morton, R. K. (1955) in Methods in Enzymology (Colowick, S. P., and Kaplan, N. O., Eds.), Vol. 1, pp. 25-51. Academic Press, San Diego. 